\title{
Emergency physicians as human billboards for injury prevention: a randomized controlled trial
}

\author{
Emily Sullivan, $\mathrm{MD}^{*}{ }^{\dagger}$; Daniel Fuller, $\mathrm{PhD}^{\ddagger}$; Quinten S. Paterson, $\mathrm{MD}^{*}$; Shelby Huffman, $\mathrm{BHSc}^{\dagger}$; \\ Satyadeva Challa, MPH ${ }^{\dagger}$; Rob Woods, MD, MMEd*
}

\section{ABSTRACT}

Objectives: The objective of this study was to evaluate the impact of a novel injury prevention intervention designed to prompt patients to initiate an injury prevention discussion with the ED physician, thus enabling injury prevention counselling and increasing bicycle helmet use among patients.

Methods: A repeated measures $2 \times 3$ randomized controlled trial design was used. Fourteen emergency physicians were observed for two shifts each between June and August 2013. Each pair of shifts was randomized to either an injury prevention shift, during which the emergency physician would wear a customized scrub top, or a control shift. The outcomes of interest were physician time spent discussing injury prevention, current helmet use, and self-reported change in helmet use rates at one year. Logistic regression analyses were used to examine the impact of the intervention. Results: The average time spent on injury prevention for all patients was 3.3 seconds. For those patients who actually received counselling, the average time spent was 17.0 seconds. The scrub top intervention did not significantly change helmet use rates at one year. The intervention also had no significant impact on patient decisions to change or reinforcement of helmet use.

Conclusions: Our study showed that the intervention did not increase physician injury prevention counselling or selfreported bicycle helmet use rates among patients. Given the study limitations, replication and extension of the intervention is warranted.

\section{RÉSUMÉ}

Objectif: L'étude décrite ici visait à évaluer la portée d'une nouvelle intervention de prévention des blessures, conçue pour inciter les patients à amorcer une discussion sur la prévention avec le médecin d'urgence, ce qui donnait l'occasion de donner des conseils sur la prévention des blessures et de favoriser le port du casque de bicyclette chez les patients. Méthode: II s'agit d'un essai comparatif avec répartition au hasard, de type $2 \times 3$, et avec reprise de mesures. Quatorze médecins d'urgence ont fait l'objet d'observation durant deux périodes de travail chacun, entre juin et août 2013. La répartition de chaque doublet vers la période de prévention des blessures au cours de laquelle le médecin d'urgence portait une blouse de chirurgie adaptée à l'intervention ou vers la période de travail témoin a été faite au hasard. Les résultats d'intérêt étaient le temps passé par le médecin à parler de la prévention des blessures, les habitudes du port du casque au moment de l'entrevue et les changements de taux de port autodéclaré du casque au bout de un an. Enfin, la portée de l'intervention a été examinée à l'aide d'analyses de régression logistique.

Résultats: Le temps moyen passé à parler de la prévention des blessures dans l'ensemble des patients était de 3,3 secondes, et celui passé chez ceux qui ont bel et bien reçu des conseils s'élevait à 17,0 secondes. L'intervention du port de la blouse de chirurgie a eu peu d'incidence sur le taux de port du casque au bout de un an et il en a été de même pour la décision des patients de changer ou de renforcer leur habitude du port du casque.

Conclusions: L'étude a démontré que l'intervention n'avait pas eu pour effet d'accroître le temps passé par les médecins à donner des conseils sur la prévention des blessures ou d'augmenter le taux de port autodéclaré du casque de bicyclette chez les patients. Compte tenu des limites de l'étude, il est justifié de répéter ou de prolonger l'intervention.

Keywords: helmet, injury prevention, emergency, randomized controlled trial

\section{INTRODUCTION}

Injuries are the leading cause of death for Canadians aged 1 to 44 years, accounting for over 15,000 deaths and over 231,000 hospitalizations annually. ${ }^{1}$ Injuries are also one of the leading causes of potential years of life lost for all Canadians under 70 years old. ${ }^{2}$ Transportrelated injuries account for $16.5 \%$ of injury deaths in

From the *Department of Emergency Medicine; †School of Public Health, University of Saskatchewan, Saskatoon, SK; and the $¥$ School of Human Kinetics and Recreation, Memorial University of Newfoundland, St. John's, NL.

Correspondence to: Emily Sullivan, Department of Emergency Medicine, Health Sciences Building, University of Saskatchewan, 107 Wiggins Road, Saskatoon, SK S7N 5E5, Canada; Email: ers044@gmail.com. 
Canada as well as $12.2 \%$ of hospitalizations due to injury. ${ }^{1}$ In 2010, there were over 3.5 million emergency department (ED) visits for injuries and 290,000 of these were transport-related. ${ }^{1}$ International estimates indicate that approximately $30 \%$ of $\mathrm{ED}$ visits are injuryrelated., ${ }^{3,4}$ The burden of transport-related injuries extends beyond health. The estimated direct cost of transport-related injuries in 2004 was $\$ 15.9$ billion, while indirect costs were estimated at $\$ 26.8$ billion. ${ }^{1}$ Many transport-related injuries are preventable and affordable injury prevention strategies exist to reduce injuries at the individual level.

In Saskatchewan, there were on average 75 bicycling injury hospitalizations among people aged 12 years and older during the years 2006-2011, inclusive. ${ }^{5}$ There were approximately 20 brain, head, scalp, skull, and face injury hospitalizations per year in Saskatchewan among the same age group in the same time period. ${ }^{5}$ Wearing a bicycle helmet is a simple, affordable, and easy injury prevention action that can be taken by any cyclist. Helmets have been shown to reduce head and brain injury by $85 \%$ and $88 \%$ respectively. ${ }^{6.7}$ A case-control study conducted in Ontario involving 129 fatalities showed that individuals who sustained a fatal head injury while cycling were 3.1 times more likely to have not been wearing a helmet. ${ }^{6}$ Evidence for the protective effect of helmets when cyclists are involved in a collision is clear. However, encouraging people to adopt helmet use is challenging, especially in Saskatchewan which does not currently have a law mandating bicycle helmet use.

Injury prevention counselling and health promotion are important components of the health care system, and the ED has an important role to play in these activities. For many people, their only contact with physicians is in EDs. ${ }^{8}$ For these patients, the ED represents a stand-in for primary care provisions. ${ }^{9-11}$ The ED may be the only source of information about injury prevention for this population. Unfortunately, health promotion and injury prevention discussions rarely occur in the ED. ${ }^{12,13}$ Even when ED physicians do provide health promotion information or counselling upon discharge these interactions are usually brief. ${ }^{14}$

When counselling and health promotion opportunities are prioritized, an ED visit can serve as a "teachable moment" - a time when the patient, having just suffered an injury, will be most likely to understand advice and consider behaviour change. ${ }^{15-17}$ This opportunity can be particularly relevant for patients presenting to the ED, as their injury may nullify misconceptions of invulnerability. ${ }^{18}$ Emergency physicians are respected health authorities, which ideally positions them to play an active role in injury prevention counselling. ${ }^{19}$

The objective of this study was to evaluate the impact of a novel injury prevention intervention designed to prompt patients to initiate an injury prevention discussion with the ED physician and thus increase the time the ED physician spent providing injury prevention counselling. Potential behaviour changes that may occur based on time spent talking about injury prevention include an increase in self-reported change in bicycle helmet wearing behaviour or reinforcement of helmet wearing behaviour at one year among patients. We chose helmet use for our injury prevention campaign because bicycle-related injuries and fatalities are common and helmet use is a simple injury prevention activity for patients to adopt. We hypothesized that the scrub top would promote injury prevention counselling among physicians and/or increase injury prevention information-seeking on the part of the patients.

\section{METHODS}

\section{Design}

A repeated measures $2 \times 3$ randomized controlled trial (RCT) design was used. The study setting was two tertiary EDs and a pediatric ED in Saskatoon, Canada. Figure 1 shows the RCT flow chart for the study. Fourteen emergency physicians were observed for two shifts each between June and August 2013. Each pair of shifts was randomized to either an injury prevention shift, during which the emergency physician would wear a customized scrub top, or a control shift. Physicians were not blinded to the scrub top intervention but were blinded to what the observer was measuring. Ethics approval was obtained from the University of Saskatchewan Behavioural Research Ethics Board.

Emergency physicians and their shifts were chosen from a convenience sample to accommodate the research assistant's schedule, the study timeline, and to obtain as many patient encounters as possible (primarily evening and weekend shifts). The research assistant observed the patient-physician interaction and recorded whether injury prevention counselling was done and for how long. The research assistant then privately surveyed the patient on their cycling and helmetwearing use and whether their visit to the ED had reinforced or changed their opinion regarding helmet 


\section{O N S O R T}

TRANSPARENT REPORTING of TRIALS

\section{CONSORT 2010 Flow Diagram}

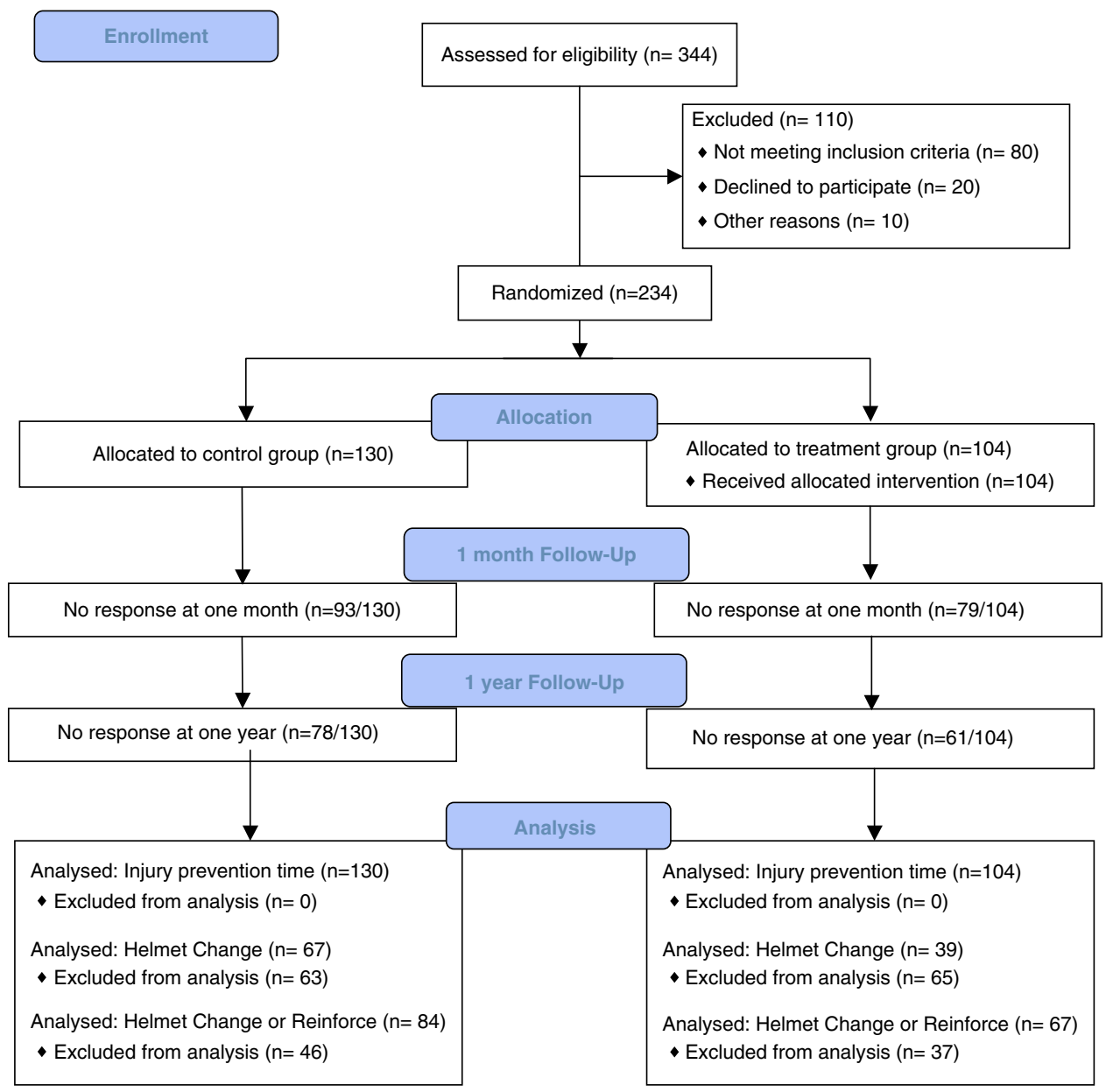

Figure 1. CONSORT Flow Diagram for physician scrub top RCT

use. Patients were then followed-up by telephone at one month and one year to reassess helmet use. Three attempts were made to contact the patients; if the research assistant was unsuccessful after the third attempt the patient was considered lost to follow-up.

The study patient population consisted of all patients who presented to the ED and were seen by the participating physicians. Patients were excluded by the research assistant if they were medically unstable, in significant distress or discomfort, were not competent, did not speak English, or had extenuating social circumstances. Written consent was obtained from all physicians and verbal consent from all patients that participated. For participants younger than 18 years of age, we obtained parental consent unless they did not live with their parents, were a university student, or visited the ED unaccompanied by his/her parent. The literature on time spent on discharge instructions from the ED is sparse, with a range of 90 seconds to 6 minutes. ${ }^{14,20,21}$ We anticipated that physicians would routinely spend approximately 90 seconds talking about injury prevention with patients who have sustained an injury and we were looking to increase this to 2 minutes when the scrub top was worn by a treating physician.

\section{Intervention}

Given the challenges to injury prevention counselling in the ED, a time-efficient and patient-driven strategy is 
desirable. We developed a novel intervention consisting of a scrub top containing injury prevention messaging that was worn by emergency physicians. The customized scrub top included the message "Put me out of work: wear your bike helmet" on the front of the top, and several bike injury statistics and an online resource for more information on the back of the top (See Figure 2). Apart from wearing the scrub top, physicians were not instructed to change their injury prevention behaviour. The intervention was provided to all patients seen by each emergency physician, regardless of age or presenting concern.

\section{Outcome Measures}

The primary outcome of interest was physician time spent discussing injury prevention. The secondary outcomes of interest were current helmet use, and longterm self-reported change in helmet wearing behaviour or helmet wearing behaviour reinforcement at one month and at one year. Counselling time was measured by observing the patient-physician interaction and timing counselling and injury prevention discussion using a stopwatch. Helmet use was measured by asking patients, "When cycling in the past year, how often have you worn a helmet?" Response options were "never", “often", "seldom", "always", “don't know", and "no response". Change in helmet wearing behaviour was measured by asking patients, "Did your visit to the Emergency Department change your decision about wearing a helmet when cycling?" Response options were "yes", "no", “don't know", and "no response".
Helmet wearing reinforcement was measured by asking "Did your visit to the Emergency Department today reinforce your decision to wear a helmet when cycling?" Response options were "yes", "no", “don't know", and "no response".

\section{Analysis}

Descriptive statistics were computed for all variables of interest. Two logistic regression models were estimated. First, a logistic regression model was estimated with injury prevention time as the outcome. Injury prevention time was dichotomized into 0 (no injury prevention time) or 1 (any injury prevention time) because the time variable was highly skewed.

Two repeated measures logistic regressions were used to examine the association between the intervention and the change in rate of helmet use, or change or reinforcement in helmet wearing behaviour. We combined the change in helmet wearing behaviour with the reinforcement in helmet wearing behaviour variable as an outcome because of concerns over missing data in the change in helmet wearing behaviour outcome. The repeated measures logistic regressions included a categorical variable for time (baseline, 1 month, 1 year), intervention (scrub top "yes" or "no"), an interaction between time and the intervention, and a fixed effect for each physician. We controlled for physician because the intervention was not blinded. Age and sex were not included in the final models as they were not effect modifiers in the association between the intervention and outcome.
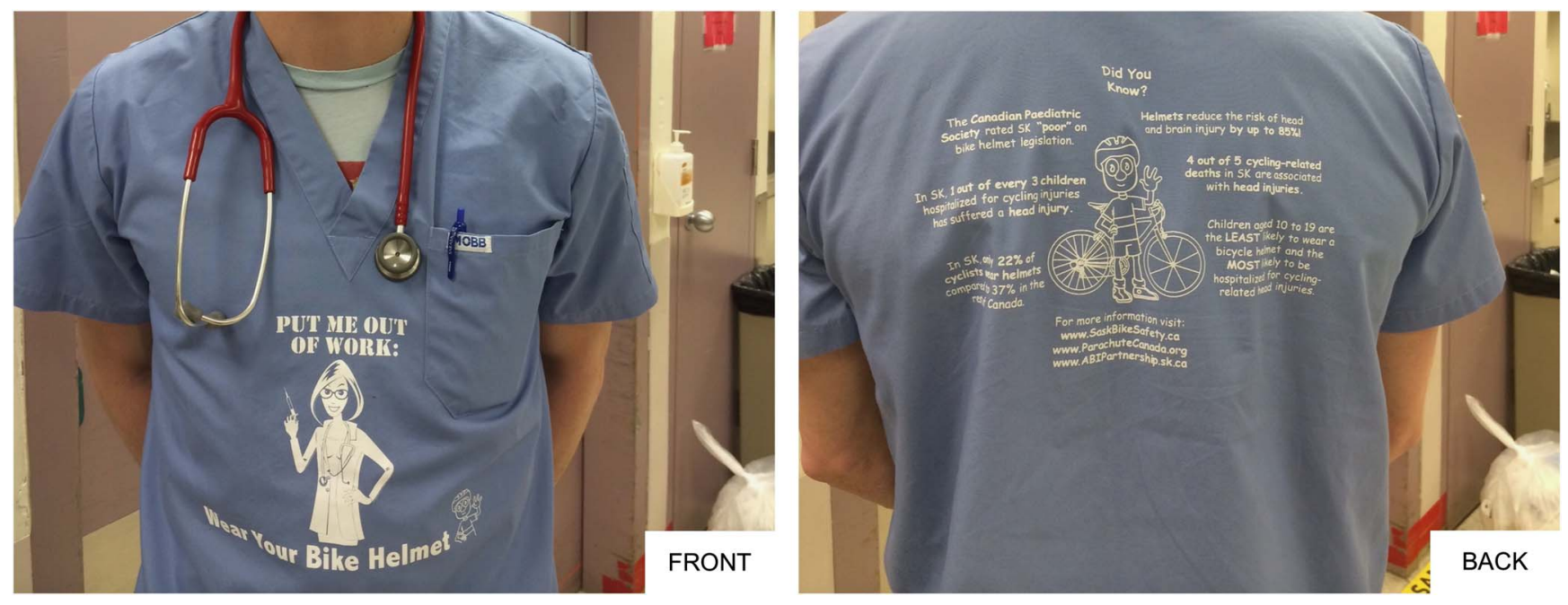

Figure 2. Photo of intervention scrub top 


\section{RESULTS}

Table 1 shows the descriptive statistics for the study. There were a total of 234 patient encounters (130 control, 104 intervention). Of the patient encounters, 30 control patient encounters and 15 intervention patient encounters received injury prevention counselling. The percent of observations contributed by each physician ranged from $7 \%$ to $19 \%$ of the total number of observations. The average time spent on injury prevention discussion for all patients was 3.3 seconds. For those patients who received counselling, the average time spent was 17.0 seconds. The most time spent on counselling during any encounter was 60 seconds. In all, 124 individuals cycled and 52 reported always wearing a helmet prior to this visit. Of patients who reported they always wore a helmet, $38 \%$ reported that the visit had reinforced their decision to wear a helmet and $23 \%$ of patients who often, seldom, or never wore a helmet reported that the visit had changed their decision to wear a helmet.

Examining the difference between injury prevention time and the intervention showed that there was no difference in the likelihood of injury prevention discussion between the treatment $(\mathrm{OR}=0.51,95 \% \mathrm{CI}$ : 0.30 to 1.16 ) and control group (see Table 2).

The impact of the scrub top intervention on patient decision to change their helmet wearing behaviour was not statistically significant. At one month and at one year the likelihood of changing helmet behaviour between the treatment and control group was 0.36 (95\% CI: 0.09 to 1.36 ) and 0.08 (95\% CI: 0.01 to 0.47 ), respectively. The likelihood of changing or reinforcing helmet behaviour between the treatment and control group was 0.53 (95\% CI: 0.16 to 1.73 ) at one month, and 0.30 (95\% CI: 0.10 to 0.84$)$ at one year.

\section{DISCUSSION}

The objective of this study was to design a simple, costeffective tool that would facilitate injury prevention discussion between emergency physicians and their patients without putting undue burden on the physician. The tool we created utilized an article of clothing that physicians wear to every shift and highlighted bicycle helmet use, and is considered a simple injury

\begin{tabular}{|c|c|c|c|c|c|c|}
\hline & \multicolumn{2}{|c|}{ Baseline } & \multicolumn{2}{|c|}{1 month } & \multicolumn{2}{|c|}{1 year } \\
\hline & $\begin{array}{l}\text { Treatment } \\
\mathrm{N}=104\end{array}$ & $\begin{array}{l}\text { Control } \\
N=130\end{array}$ & $\begin{array}{l}\text { Treatment } \\
\mathrm{N}=104\end{array}$ & $\begin{array}{l}\text { Control } \\
N=130\end{array}$ & $\begin{array}{c}\text { Treatment } \\
\mathrm{N}=104\end{array}$ & $\begin{array}{l}\text { Control } \\
N=130\end{array}$ \\
\hline $\begin{array}{l}\text { Injury prevention time in seconds } \\
\text { (Mean, SE) }\end{array}$ & $2.8(9.2)$ & $3.7(10)$ & * & & & \\
\hline \multicolumn{7}{|l|}{ Age - n (\%) } \\
\hline Less than 19 & $38(25)$ & $46(24)$ & & & & \\
\hline 19 or older & $116(75)$ & $144(76)$ & & & & \\
\hline \multicolumn{7}{|l|}{ Sex $-\mathrm{n}(\%)$} \\
\hline Male & $67(44)$ & $92(48)$ & & & & \\
\hline Female & $86(56)$ & $98(52)$ & & & & \\
\hline Injury prevention time - $\mathrm{n}(\%)$ & & & * & & & \\
\hline 0 seconds & $89(38)$ & $100(42)$ & & & & \\
\hline $1-60$ seconds & $15(7)$ & $30(13)$ & & & & \\
\hline Loss to Follow up Rate $n(\%)$ & & & $79(76 \%)$ & $93(72 \%)$ & $61(59 \%)$ & $78(60 \%)$ \\
\hline \multicolumn{7}{|l|}{ Helmet use - $\mathrm{n}(\%)$} \\
\hline Never & $33(22)$ & $47(32)$ & $8(13)$ & $16(26)$ & $12(14)$ & $15(17)$ \\
\hline Seldom & $1(1)$ & $5(3)$ & $1(2)$ & $1(2)$ & $2(2)$ & 0 \\
\hline Often & $3(2)$ & 7 (5) & $1(2)$ & $2(3)$ & $2(2)$ & $4(5)$ \\
\hline Always & $29(20)$ & $23(15)$ & $15(24)$ & $18(29)$ & $24(28)$ & $27(31)$ \\
\hline \multicolumn{7}{|c|}{ Change decision to wear helmet - $\mathrm{n}(\%)$} \\
\hline Yes & $11(13)$ & $11(13)$ & $5(18)$ & $3(11)$ & $7(22)$ & $1(3)$ \\
\hline No & $22(25)$ & $44(50)$ & $15(54)$ & $5(18)$ & $12(38)$ & $12(38)$ \\
\hline
\end{tabular}




\begin{tabular}{|c|c|c|c|}
\hline & $\begin{array}{l}\text { Time spent counselling } \\
\text { on injury prevention* } \\
\text { OR }(95 \% \mathrm{Cl})\end{array}$ & $\begin{array}{l}\text { Self-reported change } \\
\text { in helmet use }{ }^{* \wedge} \\
\text { OR }(95 \% \mathrm{Cl})\end{array}$ & $\begin{array}{l}\text { Self-reported change in helmet use or } \\
\text { reinforce the decision to use a helmet*^ } \\
\text { OR }(95 \% \mathrm{Cl})\end{array}$ \\
\hline \multicolumn{4}{|c|}{ Treatment group (ref = control) } \\
\hline Treatment & $0.51(0.25,1.02)$ & $2.59(.94,7.17)$ & $2.18(0.94,5.07)$ \\
\hline \multicolumn{4}{|l|}{ Time (ref $=0$ ) } \\
\hline 1 month & & $2.16(.95,4.85)$ & $1.54(0.68,3.50)$ \\
\hline 1 year & & $2.72(1.23,6.05)$ & $2.98(1.55,5.70)$ \\
\hline \multicolumn{4}{|l|}{ Treatment $\times$ time } \\
\hline \multicolumn{4}{|l|}{ Control $\times 1$ month } \\
\hline \multicolumn{4}{|l|}{ Control $\times 1$ year } \\
\hline Treatment $\times 1$ month & & $0.36(0.09,1.36)$ & $0.53(0.16,1.73)$ \\
\hline Treatment $\times 1$ year & & $0.08(0.01,0.47)$ & $0.30(0.10,0.84)$ \\
\hline
\end{tabular}

prevention strategy ${ }^{7}$. This tool was designed to be timeefficient with no preparation needed on the part of the physician. The tool did not add to the physicians' cognitive load; it was designed to prompt the patient to initiate injury prevention discussion rather than requiring the physician to remember to counsel the patient. Our results showed that ED physicians engaged in very little injury prevention counselling despite injuries being a common reason for ED visits and a leading cause of morbidity and mortality for all age groups. Reasons for this deficiency include real and perceived lack of time, space, funding, and support, as well as cultural and attitudinal obstacles. ${ }^{22}$

We found no difference in injury prevention behaviour among physicians in the control and intervention groups. Injury prevention discussions occurred very infrequently and only briefly in both groups. Our results showed that the scrub top intervention did not increase injury prevention activity. This highlights the issue that injury prevention rarely occurs in the ED. Similar research examining ED injury prevention following a motor vehicle collision also found visits did not serve as a teachable moment, and counselling about booster seats did not result in behaviour change at two weeks. $^{23}$

Our department is not alone in providing insufficient injury prevention activities. Less than $30 \%$ of ED chiefs reported their EDs routinely gave child passenger safety instructions to pediatric motor vehicle collision (MVC) patients and only $8.6 \%$ of pediatric MVC charts had documented safety discharge instructions. ${ }^{24}$ Macy et al. found that while $95 \%$ of pediatric emergency physicians and $82 \%$ of adult emergency physicians felt that it was their role to educate parents on child safety practices, less than half gave proper injury prevention advice in hypothetical clinical scenarios. ${ }^{25}$ Even when a department is involved in some injury prevention activities, many ED physicians and staff feel this is not enough. Garrettson et al. found that while many EDs in their study were involved in some injury prevention work, less than one quarter of respondents felt the role of injury prevention within their department was sufficient. ${ }^{22}$

Our study did not find a change in helmet wearing behaviour among patients in the intervention group compared to those in the control group. Similarly, Cushman et al. found that sustaining a bike injury and subsequently receiving health promotion counselling in the ED did not significantly increase helmet purchasing 2-3 weeks after discharge. ${ }^{26}$ Conversely, several previous studies have successfully changed helmet wearing behaviour after ED interventions. Johnston et al. found that for ED patients younger than 21 years of age, targeted behaviour change counselling resulted in increased self-reported helmet use at three and six months, though it did not change the risk of re-injury at six months. ${ }^{27}$ Bishai et al. found that children who received behavioural counselling and contracting, and children who received a free helmet were more likely to report wearing a helmet four weeks after their ED visit. ${ }^{28}$ Incorporation of a free helmet would likely have influenced the success of this intervention. A Cochrane review found interventions that provided a free helmet were more effective than education alone. ${ }^{29}$ Unfortunately, product disbursement such as this is often limited by financial and storage resources. ${ }^{30}$ 
The results of this study suggest that injury prevention is practiced very infrequently in EDs, even when facilitated by a simple intervention tool. Primary and secondary prevention is often overlooked resulting in a lost opportunity to prevent reoccurrence. Ideally, emergency physicians would have the resources and time to discuss injury prevention with all patients. We assessed our intervention on almost all patients seen by each emergency physician, regardless of age or presenting concern. It is possible that our intervention would have shown greater effect had we targeted the teachable moment and only analyzed patients who were presenting to the ED with a trauma or bicyclerelated issue.

Future studies should repeat this intervention, both with larger sample sizes and different prevention efforts (e.g., car seats) given that this injury prevention tool is simple, cost-effective, and it has very little chance of harm. Future work should include emergency nurses and allied health workers. If all staff in the ED wear the scrub tops, the message may be more visible and more likely to elicit discussion. Free or subsidized helmets could also be given to patients who reported low or non-use. This would potentially increase the efficacy of the intervention. ${ }^{7}$

\section{LIMITATIONS}

Limitations of this study included the small sample size, loss to follow-up, and incomplete interaction observation, not accounting for literacy levels, and inability to fully blind physician participants. Our study had $80 \%$ power to detect a mean difference in injury prevention time of 7 seconds between groups. Injury prevention time among physicians was short. We believe a 7 second change on average would represent a clinically meaningful change in physician behaviour. A large number of respondents were lost to follow-up at one month $(>70 \%)$ and at one year $(\sim 60 \%)$ which threatens the validity of the secondary change in behaviour measures. We included all patients presenting to the ED including but not limited to those who were there because they sustained an injury. Followup about helmet use when the presentation was not precipitated by a bicycle injury may have seemed irrelevant to most patients and as such they were not interested in participating at one month or one year. Limiting inclusion to just those patients with an injury related to the conversation about injury prevention may be more appropriate and result in better follow-up.
Only physician-patient interactions were observed. It is possible that patients had injury prevention counselling interactions with nurses or other health care professionals due to the scrub top. These potential interactions were not included in the study. Patients who did not speak English were excluded from the study, but it is possible that patients were included who spoke but could not read English. These patients would not have benefitted from the scrub top messaging. The ED physicians were blinded to the outcome measures, but were not blinded to the scrub top intervention. It is therefore possible that the physicians counselled patients more than they normally would in either arm of the trial; a type of Hawthorne effect. Since we did not have baseline counselling rates, we cannot know if this effect occurred.

\section{CONCLUSION}

Our RCT examining the impact of a customized scrub top intervention on ED physician injury prevention counselling and patient bicycle helmet use showed that the amount of time spent on injury prevention counselling was small and unrelated to the intervention. We did not observe any change in bicycle helmet related behaviours among patients who completed the follow-up. Considering the limitations of the study, replication and extension of this study may be warranted. Studying other types of simple, low cost injury prevention interventions on patients presenting to the ED with a related injury would also add to the ED injury prevention literature.

Competing Interests: None declared.

\section{REFERENCES}

1. Parachute. The Cost of Injury in Canada; 2015. Available at: http://www.parachutecanada.org/costofinjury.

2. Public Health Agency of Canada. Injury in Review - 2012 Edition; 2012. Available at: http://www.parachutecanada.org/ downloads/research/reports/InjuryInReview2012_EN.pdf.

3. Jamrozik K, Samarasundera E, Miracle R, et al. Attendance for injury at accident and emergency departments in London: a cross-sectional study. Public Health 2008;122(9):838-44.

4. Centers for Disease Control and Prevention. FastStats: Emergency Department visits;2015. Available at: http://www. cdc.gov/nchs/fastats/emergency-department.htm (accessed Feburary 2016).

5. Teschke K, Koehoorn M, Shen H, et al. Bicycling injury hospitalisation rates in Canadian jurisdictions: analyses examining associations with helmet legislation and mode share. BM7 Open 2015;5(11):e008052. 
6. Persaud N, Coleman E, Zwolakowski D, et al. Nonuse of bicycle helmets and risk of fatal head injury: A proportional mortality, case-control study. CMA7 2012;184(17):921-3.

7. Macpherson A, Spinks A. Bicycle helmet legislation for the uptake of helmet use and prevention of head injuries. Cochrane Database Syst Rev 2008;3:CD005401.

8. Canadian Institute for Health Information. Understanding Emergency Department Wait Times; 2005. Available at: https://secure.cihi.ca/free_products/Wait_times_e.pdf.

9. Guttmann A, Shipman SA, Lam K, et al. Primary care physician supply and children's health care use, access, and outcomes: findings from Canada. Pediatrics 2010;125(6):1119-26.

10. Han A, Ospina MB, Blitz S, et al. Patients presenting to the emergency department: the use of other health care services and reasons for presentation. C7EM 2007;9(6):428-34.

11. Pines JM, Hilton JA, Weber EJ, et al. International perspectives on emergency department crowding. Acad Emerg Med 2011;18(12):1358-70.

12. Anglin D, Hutson HR, Kyriacou DN. Emergency medicine residents'; perspectives on injury prevention. Ann Emerg Med 1996;28(1):31-3.

13. Demorest RA, Posner J, Osterhoudt KC, et al. Poisoning prevention education during emergency department visits for childhood poisoning. Pediatr Emerg Care 2004;20(5): 281-4.

14. Rhodes KV, Vieth $\mathrm{T}$, He $\mathrm{T}$, et al. Resuscitating the physician-patient relationship: Emergency department communication in an academic medical center. Ann Emerg Med 2004;44(3):262-7.

15. Johnston BD, Rivara FP, Droesch RM, et al. Behavior change counseling in the emergency department to reduce injury risk: A randomized, controlled trial. Pediatrics 2002; $110: 267-74$

16. Cohen DJ, Clark EC, Lawson PJ, et al. Identifying teachable moments for health behavior counseling in primary care. Patient Educ Couns 2011;85(2):8-15.

17. Flocke SA, Antognoli E, Step MM, et al. A teachable moment communication process for smoking cessation talk: description of a group randomized clinician-focused intervention. BMC Health Serv Res 2012;12(1):109-13.

18. Posner JC, Hawkins LA, Garcia-Espana F, et al. A randomized, clinical trial of a home safety intervention based in an emergency department setting. Pediatrics 2004;113(6): 1603-8.

19. Mace SE, Gerardi MJ, Dietrich AM, et al. Injury prevention and control in children. Ann Emerg Med 2001;38(4):405-14.

20. Ackermanna S, Bingisserb MB, Heierleb A, et al. Discharge communication in the emergency department: Physicians underestimate the time needed. Swiss Medical Weekly $2012 ; 142$

21. Marty H, Bogenstatter Y, Franc G, et al. How well informed are patients when leaving the emergency department? Comparing information provided and information retained. Emerg Med 7 2013;30(1):53-7.

22. Garrettson M, Weiss HB, McDonald EM, et al. A survey of ED injury prevention activities. 7 Emerg Nurs 2008; 34(1):61-8.

23. Gittelman MA, Pomerantz WJ, Laurence S. An emergency department intervention to increase booster seat use for lower socioeconomic families. Acad Emerg Med 2006;13(4): 396-400.

24. Zonfrillo MR, Nelson KA, Durbin DR. Emergency physicians' knowledge and provision of child passenger safety information. Acad Emerg Med 2011;18(2):145-51.

25. Macy ML, Clark SJ, Sasson C, et al. Emergency physician perspectives on child passenger safety: a national survey of attitudes and practices. Acad Pediatrics 2012;12(2):131-7.

26. Cushman R, Down J, MacMillan N, et al. Helmet promotion in the emergency room following a bicycle injury: a randomized trial. Pediatrics 1991;88(1):437.

27. Johnston BD, Rivara FP, Droesch RM, et al. Behavior change counseling in the emergency department to reduce injury risk: a randomized, controlled trial. Pediatrics 2002; 110(2 Pt 1):267-74.

28. Bishai D, Qureshi A, Cantu N, et al. Contracting with children and helmet distribution in the emergency department to improve bicycle helmet use. Acad Emerg Med 2003;10(12):1371-7.

29. Owen R, Kendrick D, Mulvaney C, et al. Non-legislative interventions for the promotion of cycle helmet wearing by children. Cochrane Database Syst Rev 2011;11:CD003985.

30. Zonfrillo MR, Melzer-Lange MD, et al. A comprehensive approach to pediatric injury prevention in the emergency department. Pediatr Emerg Care 2014;30(1):56-62. 